\title{
Article \\ Solid-State rGO-PEDOT:PSS Transducing Material for Cost-Effective Enzymatic Sensing
}

\author{
Firdaus Abd-Wahab, Habibah Farhana Abdul Guthoos and Wan Wardatul Amani Wan Salim * (D) \\ Department of Biotechnology Engineering, Faculty of Engineering, International Islamic University Malaysia, \\ Gombak 50728, Kuala Lumpur, Malaysia; firdaus@iium.edu.my (F.A.-W.); \\ habibahfarhana@gmail.com (H.F.A.G.) \\ * Correspondence: asalim@iium.edu.my; Tel.: +603-6196-6563
}

Received: 2 January 2019; Accepted: 21 February 2019; Published: 1 March 2019

\begin{abstract}
Performance of a sensing device is dependent on its construction material, especially for components that are directly involved in transporting and translating signals across the device. Understanding the morphology and characteristics of the material components is therefore crucial in the development of any sensing device. This work examines the morphological and electrochemical characteristics of reduced graphene oxide interspersed with poly(3,4-ethylenedioxythiophene): poly(styrenesulfonate) (rGO-PEDOT:PSS) used as a transducer material deposited on a commercially available screen-printed carbon electrode (SPCE). Electron microscopy shows that PEDOT:PSS is interspersed between $\mathrm{rGO}$ layers. Raman and XRD analyses suggest that the graphene crystallinity in GO-PEDOT:PSS and rGO-PEDOT:PSS remains intact. Instead, PEDOT:PSS undergoes a change in structure to allow PEDOT to blend into the graphene structure and partake in the $\pi-\pi$ interaction with the surface of the rGO layers. Incorporation of PEDOT:PSS also appears to improve the electrochemical behavior of the composite, leading to a higher peak current of $1.184 \mathrm{~mA}$, as measured by cyclic voltammetry, compared to $0.522 \mathrm{~mA}$ when rGO is used alone. The rGO-PEDOT:PSS transducing material blended with glucose oxidase was tested for glucose detection. The sensitivity of glucose detection was shown to be $57.3 \mu \mathrm{A} /\left(\mathrm{mM} \cdot \mathrm{cm}^{2}\right)$ with a detection limit of $86.8 \mu \mathrm{M}$.
\end{abstract}

Keywords: screen-printed carbon electrode; reduced graphene oxide; PEDOT:PSS; electrochemical reduction; glucose oxidase; cyclic voltammetry; surface characterization

\section{Introduction}

Screen-printed electrodes allow for fabrication of miniaturized and portable electrochemical devices. Among the different types of such electrodes, various portable devices have adopted the use of a screen-printed carbon-based electrode owing to its low production cost [1]. This permits the development of affordable disposable electrodes to be used in electrochemical sensors.

However, affordability of the screen-printed carbon electrode (SPCE) comes with its own limitations. Direct use of the SPCE without any modifications restricts its sensitivity and selectivity towards the electron-transfer reaction occurring at the electrode-electrolyte interface [2]. The electrode surface therefore requires some modification to increase its electrochemical activity and sensitivity. Such modifications include improving signal transduction at the electrode-electrolyte interface, either by pre-treating the electrode surface [2,3] or by incorporating better conductive and electrocatalytic materials [4]. Selecting a conductive transducer layer requires an understanding of the mechanism driving the electronic or ionic transport across the material. The faster an electron is funneled through the material, the faster that electron is transferred at the electrode surface; the transfer rate is influenced by the electrochemical characteristics of the material. 
Graphene, along with its derivatives, has been diversely used and manipulated for its surface properties. Inclusion of graphene has been shown to improve the electrochemical performance of electrodes $[5,6]$. Surface functionalization of the SPCE, either with graphene or graphene oxide, affects how charge is transferred and detected. However, functionalization of an SPCE with graphene has commonly been performed by using graphene oxide [7]. Graphene oxide is usually drop cast followed by a reduction process that turns the film into a reduced-graphene oxide structure almost like that of graphene. While chemical reduction is still used, electrochemical reduction of graphene oxide is much preferred for its rapidity and non-toxicity [8].

In developing enzymatic biosensors, construction of the transducer layer also needs to take into consideration the biorecognition element. Detection of biologics is highly dependent on the specificity and selectivity of the biorecognition element [9]. Recognition then sends an electrical or chemical signal that needs to be recognized and propagated at the transducer layer for the signal to be detected. The material used in the transducer layer should be able to accommodate and transduce the signal from the biorecognition element $[10,11]$. Measuring the signals could then be done by either impedimetric or potentiometric means; these methods of detection are commonly used in electrochemical sensor development.

Conducting polymers comprise a group of polymeric materials that, instead of being insulative, can accommodate the propagation of electrons and/or ions. Owing to this distinct characteristic, conducting polymers are sought after for use in electronic and solar applications [12]. Inclusion of conducting polymers has been shown to improve power-conversion efficiency of solar cells $[13,14]$. The use of conducting polymers as transducers has also been reported to improve the conductivity of electrodes. It has opened up the possibility of developing sensors based on solid-state electrodes [15]. One particular polymer of interest to us is a thiophene-based composite, poly(3,4-ethylenedioxythiophene):poly(styrenesulfonic acid), or PEDOT:PSS. This polymer has been reported to have high conductivity with low oxidation potential and low bandgap [16], which makes it an attractive choice in electrochemical sensors $[17,18]$. PEDOT:PSS is also regarded as an environmentally friendly and easily processable material $[16,19]$, favorable factors for device development and mass production $[17,20]$.

Incorporation of either conductive graphene or reduced graphene oxide into PEDOT:PSS has been described to help stabilize the transport layers of the polymer [13,14]. It is also reported to improve flexibility and capacitance of the composite when formed into free-standing films [21]. Yet, the contributing factor that we believe most motivates the use of reduced graphene oxide and PEDOT:PSS is the low cost of these materials for device development [14,22-24]. Most of the studies that use reduced graphene oxide with PEDOT:PSS, however, appear to reduce the graphene oxide either chemically or thermally. In this study, we reduced the graphene oxide electrochemically on the SPCE. The reduced-graphene oxide and PEDOT:PSS mixture could be directly deposited onto the surface of the transducer, which allowed for rapid prototyping and scaling-up without the need of a clean room.

Many papers discuss the applications of the composite of graphene and PEDOT:PSS, but few efforts have been made to understand the composite structure, redox behavior, surface characteristics, and feasibility as enzymatic sensors. The catalytic activity of enzymes is affected by their covalent and non-covalent interaction with an electrode material. Immobilization of enzymes on electrodes also affects its structural conformation, which in turn changes the immobilized enzymes' catalytic activity. The interaction between graphene and graphene oxide and biomolecules is reviewed elsewhere $[25,26]$. These reviews emphasize the complicated nature of the interaction between peptides and graphene or graphene oxide, and most studies rely on experimental methods to understand the interaction. One study used electrochemical polymerization of EDOT to encapsulate glucose oxidase into the PEDOT structure, thus preserving enzyme structure and catalytic capability [27]. However, the aforementioned study of encapsulating glucose oxidase with PEDOT:PSS was conducted using tubular electrodes, and sensitivity was improved with the addition of gold metal. Our fabrication 
process started with drop-casting a premixed solution consisting of glucose oxidase, PEDOT:PSS, and graphene oxide on SPCEs and subsequently reducing the drop-cast graphene electrochemically. This simple fabrication process was tested for glucose sensing to understand the limitations of the fabrication process. Studies to understand the interaction of glucose oxidase as the model enzyme with the composite are beyond the scope of this work. A simple fabrication process reduces cost and allows rapid scale-up, but the fabrication process could affect enzyme catalytic activity.

In this study, we focus on examining the characteristics of reduced graphene oxide (rGO) in a composite with PEDOT:PSS as the transducer material on SPCEs. While characterization of graphene-PEDOT:PSS has been reported previously [28], studies on the feasibility of the material to modify SPCEs for electrochemical sensing are still lacking. Reduced graphene oxide has always been likened to graphene, but with defects [29]. These defects could possibly influence the interaction between rGO and PEDOT:PSS, as well as the SPCE surface. As a transducer material, rGO-PEDOT:PSS has the potential to improve signal transduction at the electrode-electrolyte interface for better detection.

\section{Materials and Methods}

\subsection{Equipment}

A potentiostat (PocketSTAT from IVIUM Technologies, Eindhoven, the Netherlands) was used for all electrochemical measurements and reduction processes. SPCEs with active electrode diameter $\varnothing=2 \mathrm{~mm}$ were purchased from Pine Instrument Company, Grove City, PA, USA. For surface characterization of the transducer material, SEM (AURA 100 benchtop, Seron Technologies, Uiwang-si, Gyeonggi-do, Korea), and Raman spectroscopy (uRaman-M, Avantes, the Netherlands) were conducted at the Centre of Advanced Materials, University of Malaya, Selangor, Malaysia. TEM (Tecnai F20 X-Twin FEI, Thermo Fisher Scientific, Waltham, MA, USA) was done at the Malaysian Institute of Microelectronics Systems (MIMOS), BERHAD Technology Park, Seri Kembangan, Malaysia, FTIR spectrometer (Nicolet ${ }^{\mathrm{TM}}$ iS50, Thermo Fisher Scientific) at The International Institute for Halal Research and Training (INHART), IIUM, Selangor, Malaysia, and XRD (Bruker D8 Advance, Bruker Corporation, Billerica, MA, USA) at Universiti Kebangsaan Malaysia Research Centre, Bangi, Selangor, Malaysia.

\subsection{Material and Reagents}

Ultra-highly concentrated single-layer graphene oxide (UHC GO, $6.2 \mathrm{mg} / \mathrm{ml}$ ) was purchased from Graphene Supermarket (Richmond, NY, USA). Poly (3, 4-ethylenedioxythiophene): polystyrenesulfonic acid (PEDOT:PSS, 483095) was purchased from Sigma-Aldrich, St. Louis, MO, USA. Potassium dihydrogen phosphate $\left(\mathrm{KH}_{2} \mathrm{PO}_{4}, 795488\right)$ and disodium hydrogen phosphate $\left(\mathrm{Na}_{2} \mathrm{HPO}_{4}, 71640\right)$ to prepare $0.1 \mathrm{M}$ phosphate buffered saline (PBS), $\mathrm{pH} 5$, were also obtained from Sigma-Aldrich. Potassium ferricyanide $\left(\mathrm{K}_{3} \mathrm{Fe}(\mathrm{CN})_{6}, 6969-00\right)$ was purchased from R\&M Chemicals, Selangor, Malaysia. Deionized (DI) water was used whenever required throughout experiments.

\subsection{Preparation of $r G O$ and $r G O-P E D O T: P S S$ Electrodes}

To prepare an $\mathrm{rGO} / \mathrm{SPCE}, 3 \mu \mathrm{L}$ UHC GO was drop-cast onto the working electrode (WE) of the SPCE and left to dry in ambient conditions. To prepare an rGO-PEDOT:PSS/SPCE, GO and PEDOT:PSS at a ratio of 1:1 were mixed, sonicated at $30^{\circ} \mathrm{C}$ for $10 \mathrm{~min}$, drop-cast onto the WE of the SPCE, and dried in ambient conditions. All drop-cast electrodes were reduced via electrochemical reduction using repetitive cyclic voltammetry $(\mathrm{CV})$ for 15 cycles at scanning potential of $0 \mathrm{~V}$ to $-1.5 \mathrm{~V}$ and scan rate of $0.1 \mathrm{~V} / \mathrm{s}$ in $0.05 \mathrm{M} \mathrm{PBS}, \mathrm{pH} 5.0$ (disodium hydrogen phosphate/potassium dihydrogen phosphate; $\left.\mathrm{NaHPO}_{4} / \mathrm{KH}_{2} \mathrm{PO}_{4}\right)$. The modified electrodes were rinsed with deionized water and dried in ambient conditions. 


\subsection{Surface Characterization}

The morphologies of graphene and graphene-based nanocomposites were observed by SEM (AURA 100 benchtop) with a power setting of $5.0 \mathrm{kV}$ and magnification settings of 10X. The Tecnai TF20 $X$-Twin FEI operating at an accelerating voltage of $200 \mathrm{kV}$ was used to obtain TEM images of the samples. For the infrared spectra of graphene and graphene-based nanocomposites, a FTIR spectrophotometer (Nicolet ${ }^{\mathrm{TM}}$ iS50) was used, and the spectra were recorded in the range between 600 and $4000 \mathrm{~cm}^{-1}$, while the Raman spectra of the samples were recorded between 400 and $3000 \mathrm{~cm}^{-1}$ with a uRaman-M microscope using a 532-nm excitation wavelength. A Bruker D8 Advance instrument using $\mathrm{Cu} \mathrm{K} \alpha$ radiation under a voltage of $40 \mathrm{kV}$ and a current of $40 \mathrm{~mA}$ was used to perform XRD analyses, and the refraction data of the thin-film samples were recorded for $2 \theta$ angles between 5 and 60 degrees.

\subsection{Cyclic Voltammetry of rGO/SPCE and rGO-PEDOT:PSS/SPCE}

Cyclic voltammetry is an electrochemical analysis conducted when a potential voltage is applied to an electrode setup consisting of working and reference electrodes; a current response is measured using a potentiostat against a reference electrode-typically an $\mathrm{Ag} / \mathrm{AgCl}$ electrode. $\mathrm{CV}$ was performed on the unmodified SPCE, rGO/SPCE, and rGO-PEDOT:PSS/SPCE in a redox-active solution of $0.1 \mathrm{M}$ potassium ferricyanide $\left(\mathrm{K}_{3} \mathrm{Fe}(\mathrm{CN})_{6}\right)$. This method was used to understand the electrochemical redox behavior of the material deposited on the WE surface. The oxidation/reduction peak current $\left(\mathrm{I}_{\mathrm{p} a / \mathrm{c}}\right)$ of the electrode was determined by the Randles-Sevcik equation:

$$
\mathrm{I}_{\mathrm{p} \mathrm{a} / \mathrm{c}}=\left(2.69 \times 10^{5}\right) n^{3 / 2} \mathrm{D}^{1 / 2} \mathrm{C} \mathrm{A} v^{1 / 2},
$$

where $n$ is the number of transferred electrons for the redox reaction, $\mathrm{D}$ is the diffusion coefficient $\left(6.70 \times 10^{-6} \mathrm{~cm}^{2} \mathrm{~s}^{-2}\right), \mathrm{C}$ is the molar concentration of ferricyanide $(0.1 \mathrm{M}), \mathrm{A}$ is the effective surface area $\left(\mathrm{cm}^{2}\right)$, and $v$ is the scan rate $\left(\mathrm{mV} \mathrm{s}^{-1}\right)$.

For the effective surface area of both modified and unmodified SPCEs, CV was performed at scan rates of 25, 50,100, and $150 \mathrm{mV} / \mathrm{s}$; from equation (1), a well-established linear relationship exists between $\mathrm{I}_{\mathrm{p}}$ and $v^{1 / 2}$. By performing linear regression for $\mathrm{I}_{\mathrm{p}}$ versus $v^{1 / 2}$, the slope $k$ can be obtained, and one may express A as:

$$
\mathrm{A}=k /\left(\left(2.69 \times 10^{5}\right) \mathrm{n}^{3 / 2} \mathrm{D}^{1 / 2} \mathrm{C}\right)
$$

\section{Results and Discussion}

\subsection{Surface Morphologies and Characterization}

The fabrication process of the modified SPCE electrode is shown in Figure 1. The graphene oxide that was initially mixed with PEDOT:PSS was electrochemically reduced to convert the composite into rGO-PEDOT:PSS. The reduction process removed the oxygenated functional groups at the edges of the graphene oxide, thereby eliminating some of its insulative properties [29].

The surface morphology of screen-printed carbon electrodes modified with reduced graphene oxide dispersed in PEDOT/PSS was characterized under SEM and compared to the morphologies of those modified with PEDOT/PSS and graphene oxide.

Reduced graphene oxide appeared to be flaky, resembling the pattern of a crumpled sheet with discernable spacing between the rGO layers (Figure 2a). This could be attributed to the re-formation of the $\pi-\pi$ stacking between the layers as a result of electrochemical reduction [30]. With the inclusion of PEDOT:PSS into rGO (Figure 2d), the interlayer spacing of rGO appeared to be filled with PEDOT:PSS, suggesting that the $\pi-\pi$ interaction was now taking place between the rGO and the PEDOT:PSS [31]. This was further confirmed by TEM (Figure 3). 


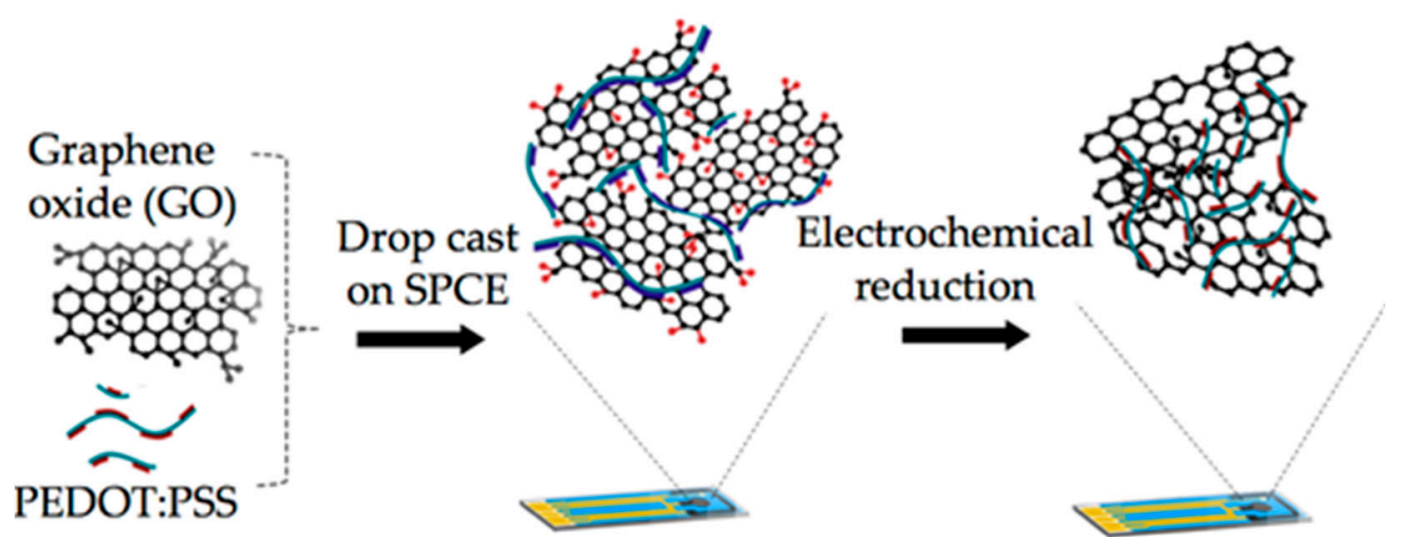

Figure 1. Schematic illustration of the modification done on the screen-printed carbon electrodes (SPCEs). Commercially available ultra-highly concentrated graphene oxide was initially mixed at a ratio of 1:1 with PEDOT:PSS before being drop-cast onto the working electrode of the SPCE and left to dry at room temperature, resulting in the formation of a GO-PEDOT:PSS/SPCE electrode. Subsequent electrochemical reduction would then form the rGO-PEDOT:PSS/SPCE electrode.

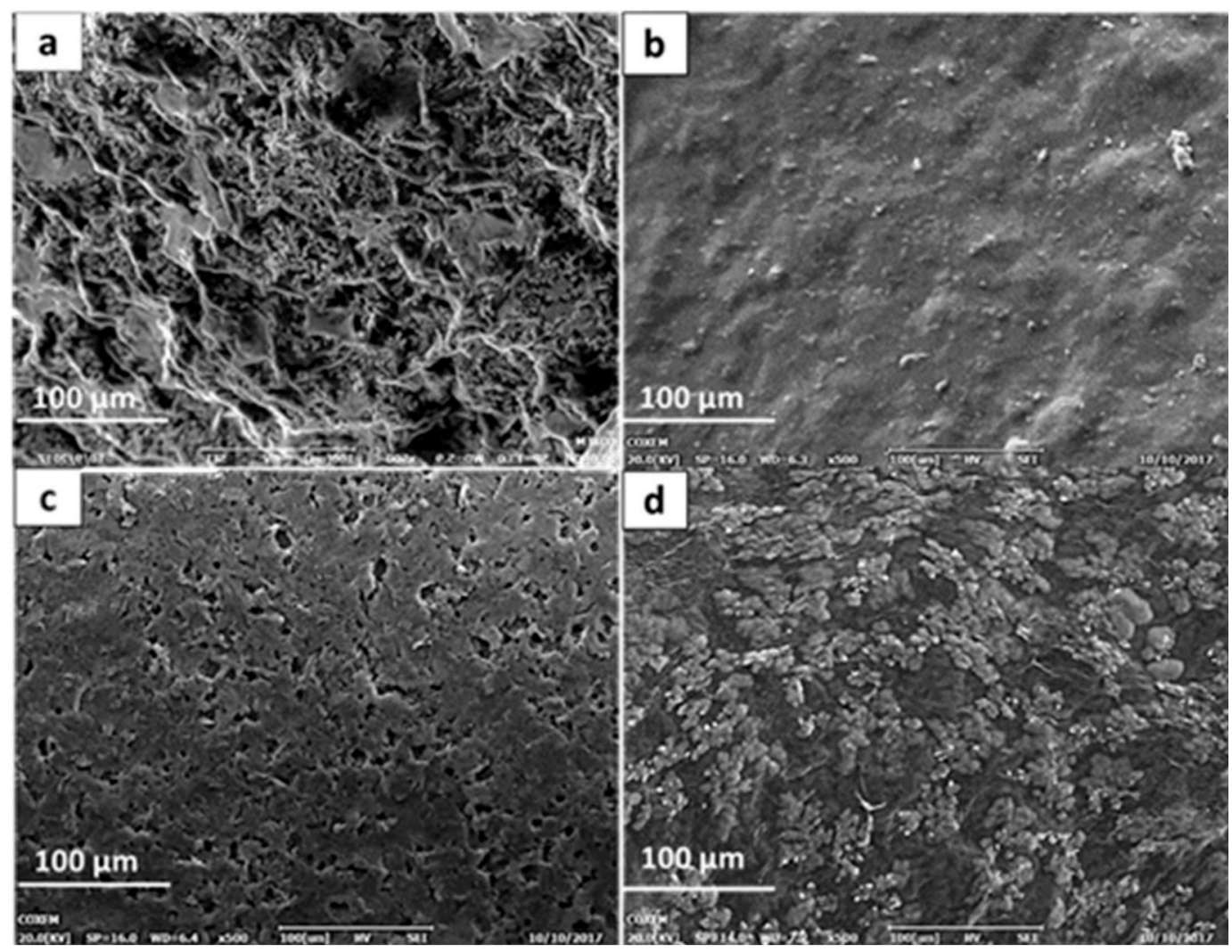

Figure 2. SEM images at 10x magnification of SPCE modified with (a) rGO, (b) PEDOT:PSS, (c) GO-PEDOT:PSS, and (d) rGO-PEDOT:PSS. The rGO layers appeared flaky with a discernible spacing between layers, whereas the PEDOT-PSS appeared as a well-dispersed surface of colloids. The rGO-PEDOT:PSS composite layer appeared to form a dispersion of colloidal aggregates that occupied the interlayer spacing. This dispersion appeared to be different compared to the GO-PEDOT:PSS composite layer, which may have been attributed to the different stacking characteristic of GO and rGO. 


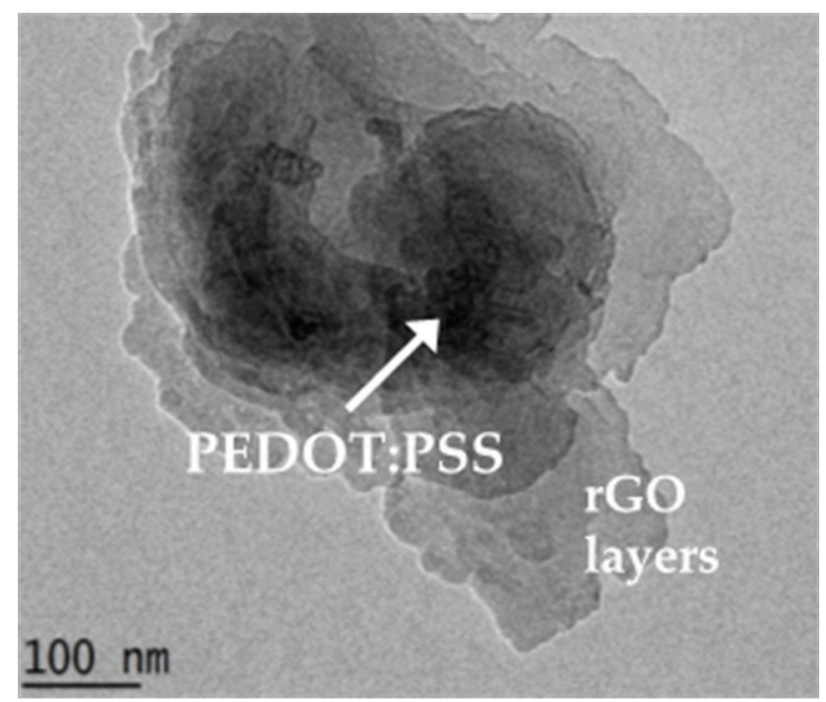

Figure 3. TEM image of the rGO-PEDOT:PSS composite. PEDOT:PSS appeared to be present between the rGO layers, as implied in the image by the darker impression within the rGO layers.

The TEM image shows several layers of rGO with inter-dispersion of PEDOT:PSS, which appeared as a darker layer. This shows that PEDOT:PSS had diffused into the layers of the stacking and formed the $\pi-\pi$ interaction between PEDOT:PSS and the surface of the rGO layers [21,32]. The rGO layer image is in congruence with the images from Abdolhosseinzadeh et al. [32], and the rGO-PEDOT:PSS agrees with Chen et al. [31].

Comparing Figure $2 \mathrm{c}, \mathrm{d}$, the difference in morphology may suggest that the interaction between rGO and PEDOT:PSS was continuous and well dispersed compared to GO-PEDOT:PSS. Bundles of aggregated graphene and polymer could be seen in Figure $2 \mathrm{~d}$, which could be related to the PEDOT aggregation as the PSS formed the tightly coated layer with rGO.

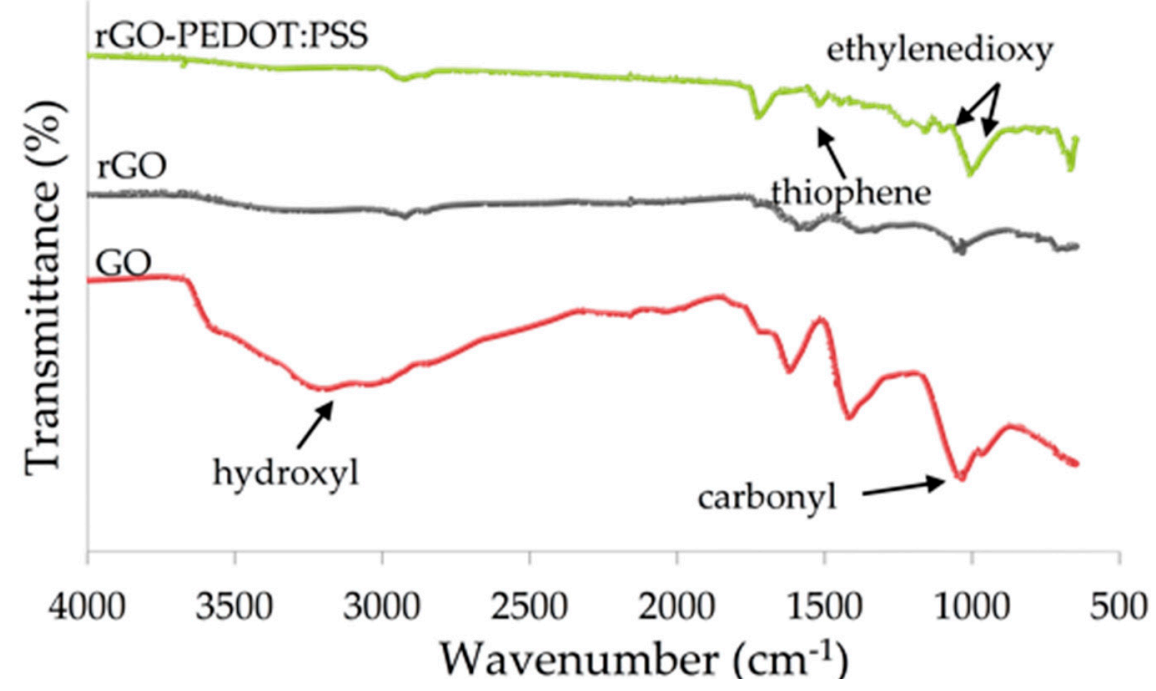

Figure 4. FTIR analysis of the transducer materials. The FTIR plots compare the functional-group composition between GO (red), rGO (grey), and rGO-PEDOT:PSS (green).

The FTIR results in Figure 4 show the removal of oxygenated functional groups from rGO compared to GO. The removal of the hydroxyl group was most distinct, as shown by the absence of transmittance at $3400 \mathrm{~cm}^{-1}$. Removal of the carbonyl groups from rGO was also suggested by the reduction in vibration at $1084 \mathrm{~cm}^{-1}$. This suggests that reduction of rGO could be done electrochemically on the SPCE surface. 
Comparison of the FTIR spectra of rGO and rGO-PEDOT:PSS suggests the formation of new bond types in rGO-PEDOT:PSS. The reappearance of vibration at $1090 \mathrm{~cm}^{-1}$ was suggested to correspond to the sulfone groups of the PSS molecules. Peaks at $1513 \mathrm{~cm}^{-1}$ corresponded to the $\mathrm{C}=\mathrm{C}$ stretching in thiophene; stretching of the ethylenedioxy group could be seen by the vibrations at $1145 \mathrm{~cm}^{-1}$ and $1056 \mathrm{~cm}^{-1}$.

The spectrum confirmed the reduction of graphene oxide as well as the dispersion of PEDOT:PSS in rGO. Interestingly, the band at $1726 \mathrm{~cm}^{-1}$, which was attributed to the graphitic $\mathrm{C}=\mathrm{O}$ group, could be seen in the rGO-PEDOT:PSS spectrum [33]. This suggests that the rGO was partially reduced but sufficient enough to form the $\pi-\pi$ interaction with PEDOT:PSS [34].

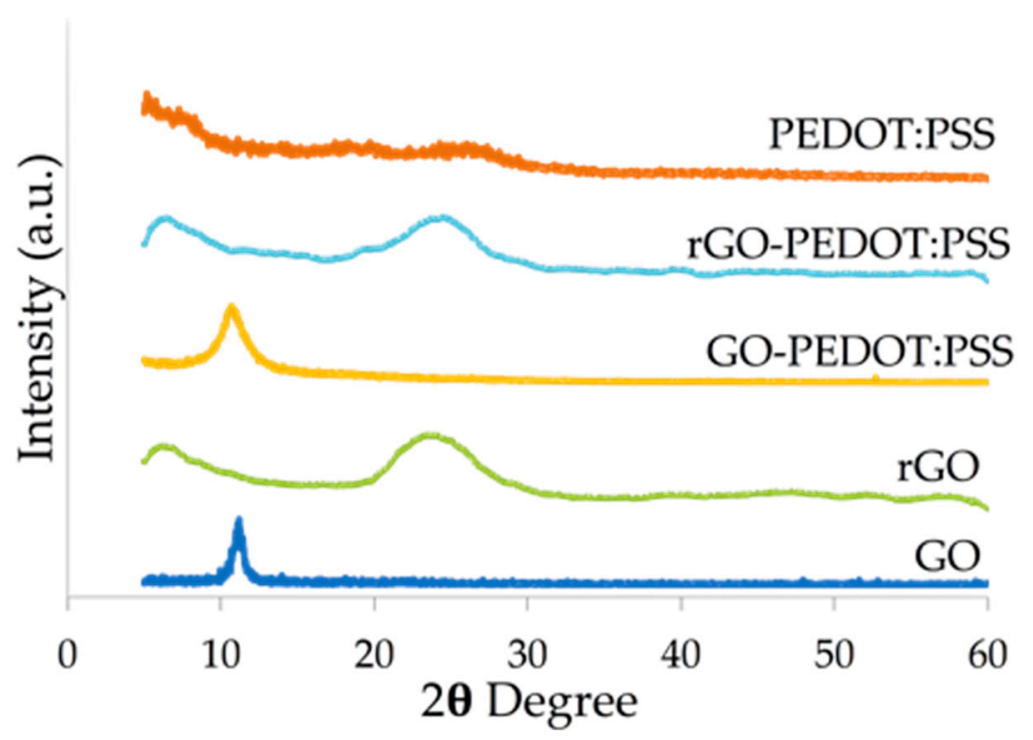

Figure 5. X-ray diffraction intensities of the different transducer composites. The XRD spectrum compares the diffraction between GO, rGO, GO-PEDOT:PSS, rGO-PEDOT:PSS, and PEDOT:PSS. Shift in the $2 \theta$ angle could be seen between GO and rGO in the spectra both with and without PEDOT:PSS. The peak intensities for GO and GO-PEDOT:PSS were observed at $10.7^{\circ}$ and $10.3^{\circ}$, respectively, whereas for rGO and rGO-PEDOT:PSS, they were observed at $24.5^{\circ}$ and $23.5^{\circ}$, respectively.

The XRD plot in Figure 5 shows a shift in the $2 \theta$ angle between the GO and the rGO. This shift confirmed the reaggregation of the rGO layers forming the $\pi-\pi$ interaction between stacks. The reduction to $\mathrm{rGO}$ reestablished an sp2 carbon network that resembled that of graphene, but also caused defects to form in rGO [35]. This was shown by the broad band of the diffraction in rGO and rGO-PEDOT:PSS compared to the sharp peak in GO and GO-PEDOT:PSS. However, the XRD data confirmed only the electrochemical reduction of $\mathrm{rGO}$ and rGO-PEDOT:PSS and not the dispersion of PEDOT:PSS in GO and rGO. From the diffraction data, the distance between layers could be calculated by Bragg's Law. GO and GO-PEDOT:PSS had a layer distance of $7.95 \AA$ and $8.30 \AA$, respectively, whereas rGO and rGO-PEDOT:PSS had a smaller layer distance of $3.85 \AA$ and $3.55 \AA$, respectively. This again reconfirmed that while GO layers were separated, rGO layers were close enough to form an interlayer interaction. It is still possible that with the inclusion of PEDOT:PSS in the matrix of rGO, the $\pi-\pi$ interaction was formed between the surface of rGO and PEDOT:PSS [21].

Figure 6 shows the Raman spectra of rGO, PEDOT:PSS, GO-PEDOT:PSS, and rGO-PEDOT:PSS. Two main peaks were clearly visible from the Raman spectra of all the graphene based-modified electrodes-the $\mathrm{G}\left(1580 \mathrm{~cm}^{-1}\right)$ and $\mathrm{D}\left(1350 \mathrm{~cm}^{-1}\right)$ bands. The higher $\mathrm{D}$ bands in both rGO and rGO-PEDOT:PSS compared to their G bands concurred with the expected graphitic defects of a reduced graphene oxide. The reduction process, which removed oxygen functional groups from an otherwise insulative graphene oxide, caused an increase in the out-of-plane sp2 vibrations of the carbon lattice [36]. This resulted in a higher D-band intensity in the Raman scattering. PEDOT:PSS 
could be clearly discerned by its characteristic vibration at $1434 \mathrm{~cm}^{-1}$, which was attributed to the stretching of the thiophene ring [37]. The presence of PEDOT:PSS in the rGO-PEDOT:PSS could barely be detected by a slight increase in the vibration between the $\mathrm{D}$ and $\mathrm{G}$ peaks compared to those of rGO. The weak detection here may have been due to the weak intensity obtained from the Raman data. Nonetheless, the presence of PEDOT:PSS was confirmed by other methods of detection, and the Raman data reconfirmed it, as well as showing the reduction of graphene oxide. It has been suggested that the thiophene-related band of PEDOT:PSS diminishes with respect to the graphitic D and G bands in rGO-PEDOT:PSS because PEDOT:PSS undergoes a structural change to facilitate the formation of a new $\pi-\pi$ interaction between PEDOT and the surface of the graphitic layers [31]. This new formation forms a tight matrix within the rGO-PEDOT:PSS composite. PEDOT is known to be the molecular backbone of the conducting polymer, which acts as the hole carrier that transports charges between the valence and conduction bands [38]. In addition to the conductive behavior of rGO, inclusion of PEDOT:PSS could potentially improve conductivity of the composite. It is therefore interesting to examine the electrochemical performance of electrodes modified with rGO-PEDOT:PSS and compare it with that of rGO alone.

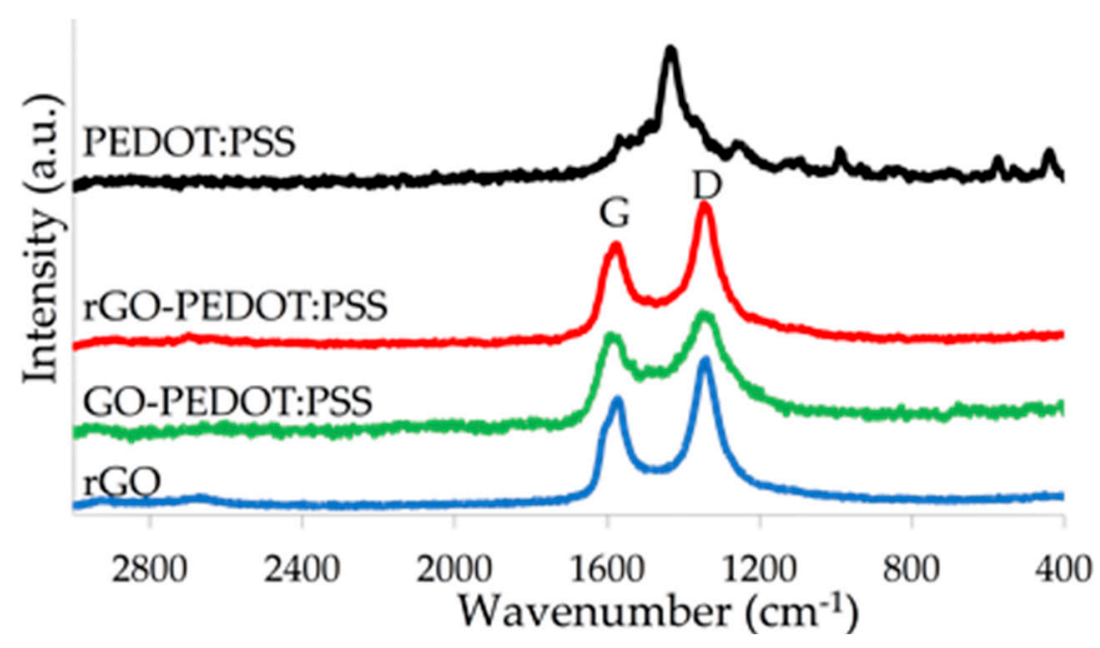

Figure 6. Raman spectra of rGO (blue), PEDOT:PSS (black), GO-PEDOT:PSS (green), and rGO-PEDOT:PSS (red). The D and G bands of rGO, GO-PEDOT:PSS, and rGO-PEDOT:PSS were clearly visible in the spectra, whereas the PEDOT:PSS spectrum showed a clear thiophene peak at $1434 \mathrm{~cm}^{-1}$. A raised intensity at $1434 \mathrm{~cm}^{-1}$ in both the GO-PEDOT:PSS and rGO-PEDOT:PSS spectra, compared to rGO, suggests the presence of PEDOT:PSS in the composite.

\subsection{Cyclic Voltammetric Comparison between rGO and rGO-PEDOT:PSS}

Cyclic voltammetry comparison between rGO and rGO-PEDOT:PSS corroborated the characteristic contribution of PEDOT:PSS as a conducting polymer. It can be seen in Figure 7 that the peak current increased with the addition of PEDOT:PSS when comparing voltammograms of electrodes modified with rGO and with rGO-PEDOT:PSS. The result shows that the redox reaction at all electrodes in ferricyanide solution was reversible with oxidation and reduction. The rGO-PEDOT:PSS/SPCE $\left(\mathrm{I}_{\mathrm{pa}}=1.005 \mathrm{~mA}\right)$ exhibited larger current responses and better defined redox peaks towards analytes than did the $\mathrm{rGO} / \mathrm{SPCE}\left(\mathrm{I}_{\mathrm{pa}}=0.613 \mathrm{~mA}\right)$ and unmodified SPCE $\left(\mathrm{I}_{\mathrm{pa}}=0.024 \mathrm{~mA}\right)$.

Modifying the electrode with rGO alone caused an increase in the peak current. This improvement in current transduction was brought about by the conductivity of the rGO, which propagated charge through its $\pi$-cloud [39]. Further incorporation of PEDOT:PSS then further increased the charge transport through the rGO-PEDOT:PSS matrix. This suggested that as the PEDOT:PSS layers were now forming the $\pi-\pi$ interaction with $\mathrm{rGO}$, electron (hole) transport along the conducting polymer contributed towards increasing the charge transfer between the electrode and the electrolyte [40]. It is 
likely that charge transfer was improved owing to the increased availability of $\pi$-bonding aromatic rings, which led to higher occurrence in the $\pi-\pi$ overlap [41]. A larger number of $\pi-\pi$ overlaps contributed to more electron delocalization around the aromatic ring, thus creating a favorable condition for electrical conductivity [42].

Shifts in the peak potential, $E_{p}$, at the scan rate of $100 \mathrm{mV} / \mathrm{s}$ for SPCE, $\mathrm{rGO} / \mathrm{SPCE}$, and rGO-PEDOT:PSS/SPCE were also observed. The peak potentials were $\mathrm{E}_{\mathrm{pa}}=0.43 \mathrm{~V}$, and $\mathrm{E}_{\mathrm{pc}}=-0.17 \mathrm{~V}$ for unmodified SPCE, $\mathrm{E}_{\mathrm{pa}}=0.28 \mathrm{~V}$ and $\mathrm{E}_{\mathrm{pc}}=-0.05 \mathrm{~V}$ for $\mathrm{rGO} / \mathrm{SPCE}$, and $\mathrm{E}_{\mathrm{pa}}=0.34 \mathrm{~V}$ and $\mathrm{E}_{\mathrm{pc}}=-0.11 \mathrm{~V}$ for rGO:PEDOT:PSS $/ \mathrm{SPCE}$, respectively. The difference between the two peak potentials $\left(\triangle \mathrm{Ep}=\mathrm{E}_{\mathrm{pa}}-\mathrm{E}_{\mathrm{pc}}\right.$ ) was calculated to be $0.6 \mathrm{~V}, 0.33 \mathrm{~V}$, and $0.45 \mathrm{~V}$ for SPCE, rGO/SPCE, and rGO-PEDOT:PSS/SPCE, respectively. The lower potential difference for $\mathrm{rGO} / \mathrm{SPCE}$ and rGO-PEDOT:PSS/SPCE indicated improved electrocatalytic ability of a modified electrode compared to an unmodified one. Overall, the addition of rGO-PEDOT:PSS to SPCEs contributed to faster electron transfer between electrode surface and electrolyte, making this composite a suitable transducer for biosensing purposes.

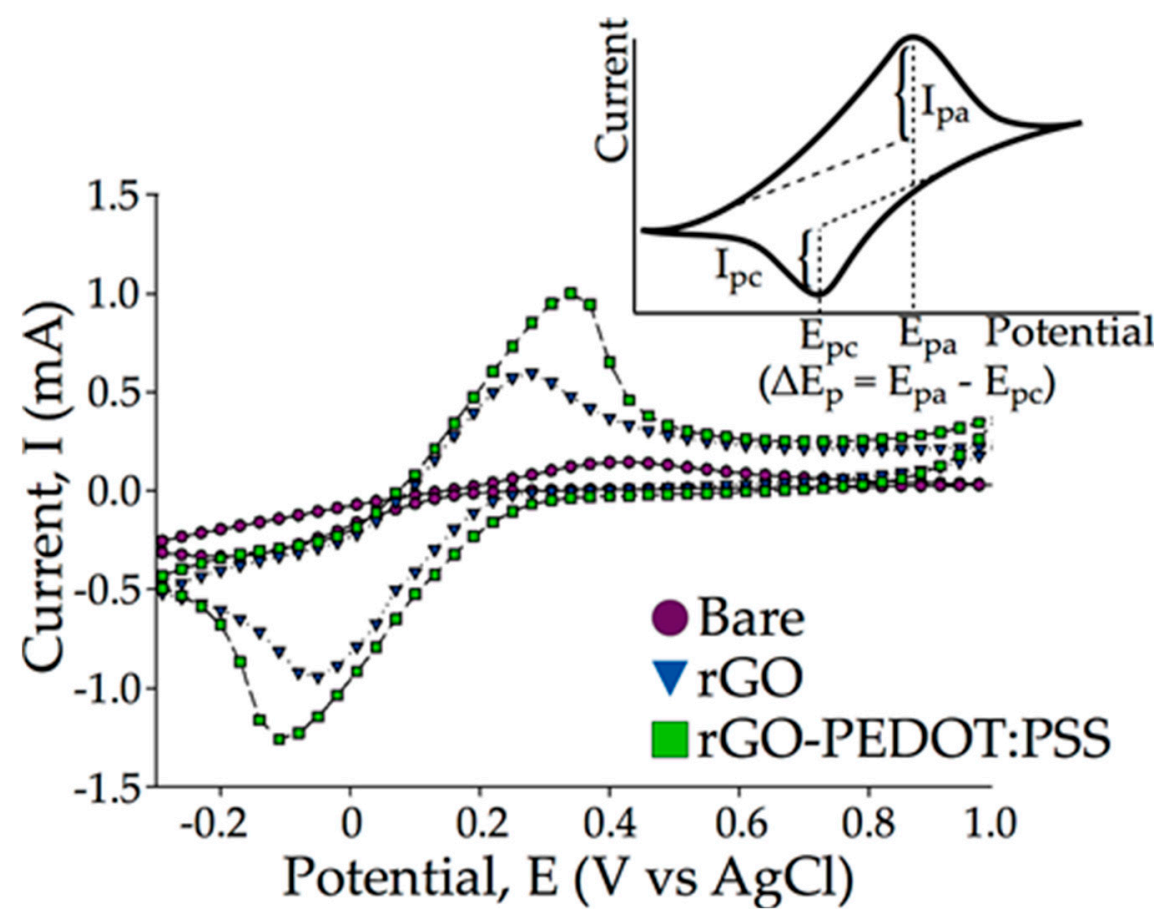

Figure 7. Cyclic voltammetry (CV) measurements of rGO-PEDOT:PSS/SPCE compared to those for rGO/SPCE and a bare SPCE. The peak currents for both oxidation and reduction cycles were measured as the vertical distance between the highest current peak with respect to the linear projection of the baseline of the respective curves. The anodic peak currents $\left(I_{p a}\right)$ for SPCE, rGO/SPCE, and rGO-PEDOT:PSS/SPCE were measured as $0.024 \mathrm{~mA}, 0.613 \mathrm{~mA}$, and $1.005 \mathrm{~mA}$, respectively. Shift in the peak potential could also be observed from the voltammogram. The shift in peak potential for each $\mathrm{CV}$ measurement was measured as the difference between the anodic peak potential and the cathodic peak potential, $\left(\Delta \mathrm{Ep}=\mathrm{E}_{\mathrm{pa}}-\mathrm{E}_{\mathrm{pc}}\right)$. Inset figure illustrates how peak currents and peak potential shift were calculated. 
a)
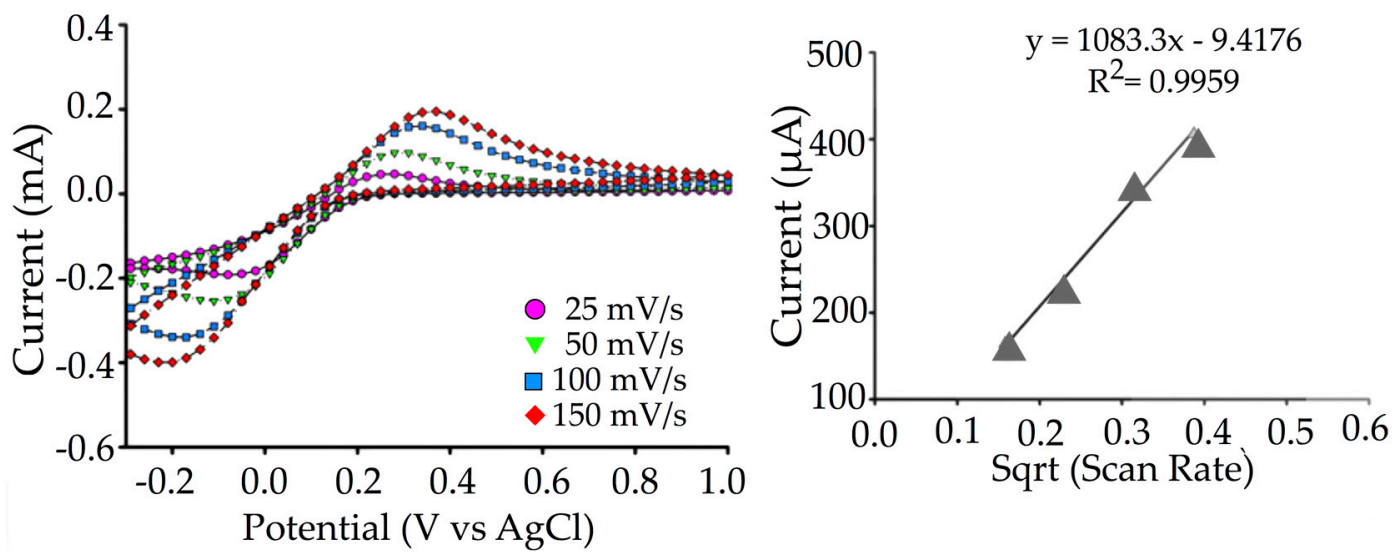

b)
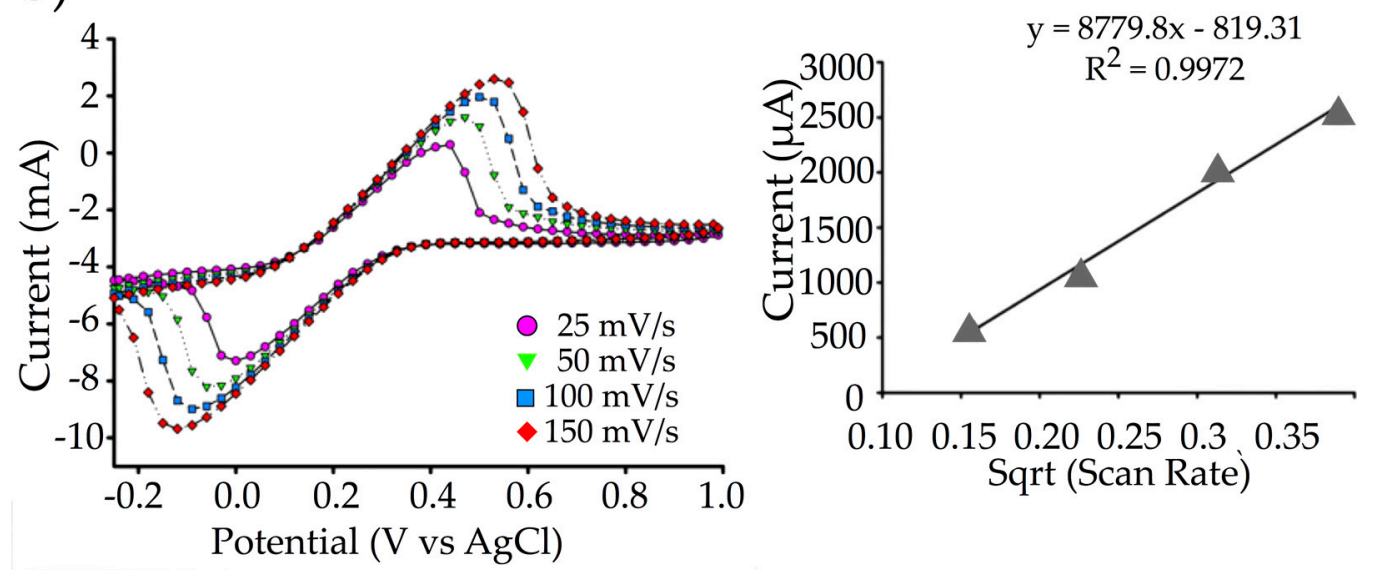

c)
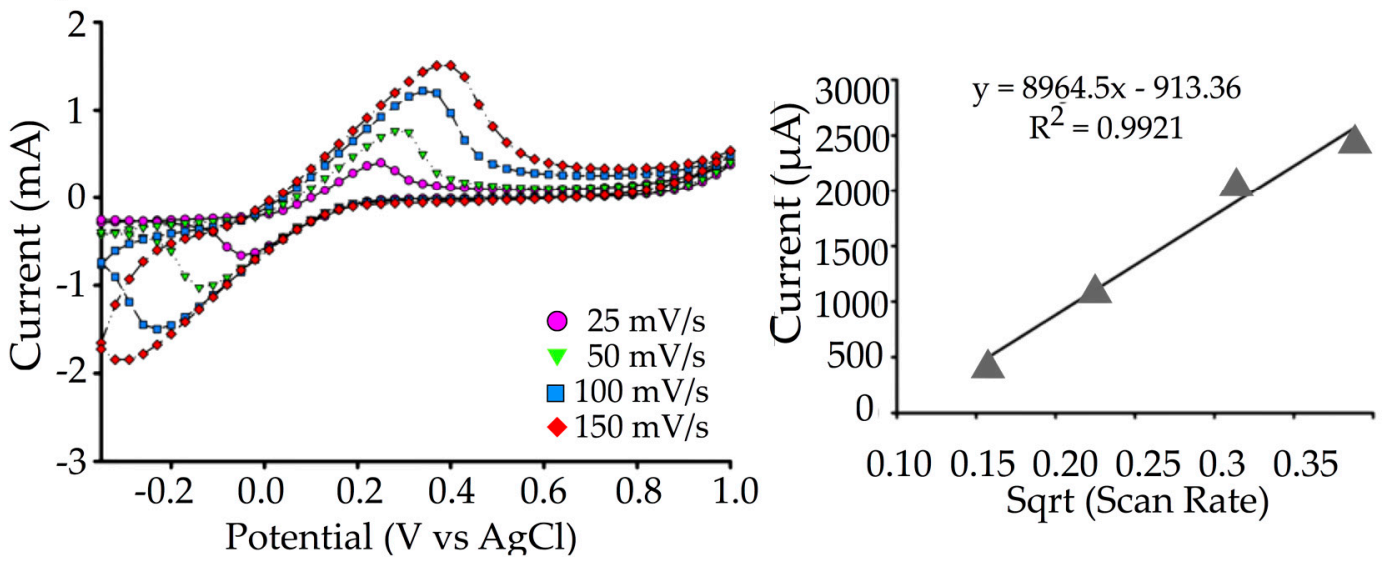

Figure 8. Scan-rate measurements of (a) SPCE, (b) rGO/SPCE, and (c) rGO-PEDOT:PSS/SPCE. Cyclic voltammetric measurements were taken at scan rates of 25, 50, 100, and $150 \mathrm{mV} / \mathrm{s}$. Linear regression plots were derived from the scan-rate voltammogram by plotting the corresponding peak currents and potentials at each scan rate.

Figure 8 shows the individual voltammograms of the SPCE, rGO/SPCE, and rGO-PEDOT:PSS/SPCE in potassium ferricyanide $\left(\mathrm{K}_{3} \mathrm{Fe}(\mathrm{CN})_{6}\right)$ solution at different scan rates 
$(25,50,100$, and $150 \mathrm{mV} / \mathrm{s})$ and their corresponding linear regression plots. The results show that the current and peak potential increased linearly with the scan rate for all three electrode types. This suggests that the redox current of all electrode types in ferricyanide solution was dependent on the scan rate. In addition, the effective surface area was also calculated based on the Randles-Sevcik equation. The calculated effective surface areas for SPCE, rGO/SPCE, and rGO-PEDOT:PSS/SPCE were $1.6 \mathrm{~mm}^{2}, 12.6 \mathrm{~mm}^{2}$ and $12.9 \mathrm{~mm}^{2}$, respectively. The large increase in effective surface area of the rGO/SPCE and rGO-PEDOT:PSS/SPCE in comparison to the SPCE could be attributed to the increase in the charge transferability and current density. The slight increment between $\mathrm{rGO} / \mathrm{SPCE}$ and rGO-PEDOT:PSS/SPCE effective surface area, on the other hand, could be related to the tight layer of the PEDOT:PSS aggregates occupying the interlayer spacing between the rGO surfaces $[21,31,38]$.

\section{3. $r$ GO-PEDOT:PSS as a Transducer in Enzymatic Sensing}

Suitability of the rGO-PEDOT:PSS composite for use in enzymatic-based sensors was then tested. Glucose oxidase (GOx) was used as our model enzyme because its use is well established in glucose biosensors, and its mechanism of reaction is known [43]. Glucose oxidase was incorporated into the transducer composite to form a homogeneous biorecognition-transducer complex (rGO-PEDOT:PSS-GOx).

Figure 9a shows a sample of the amperometric current versus time curve of glucose introduced onto the rGO-PEDOT:PSS-GOx electrode. Incremental addition of glucose onto the electrode resulted in a stepwise increase in current. This suggests that the electrode could detect changes in glucose concentration within the range of $100 \mu \mathrm{M}$ to $600 \mu \mathrm{M}$. This is also reflected by the linear plot throughout the calibration curve in Figure 9b. From here, the sensitivity of the glucose detection was obtained as $57.3 \mu \mathrm{A} /\left(\mathrm{mM} \cdot \mathrm{cm}^{2}\right)$ and its limit of detection at $86.8 \mu \mathrm{M}$ glucose, per standard calculation $[44,45]$. The sensitivity and limit of detection of this initial setup appeared to be within an acceptable range compared with those of other modified electrodes [46].

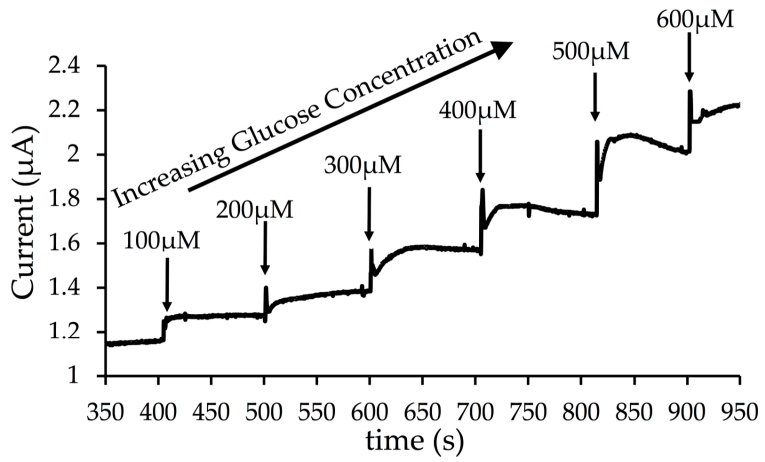

(a)

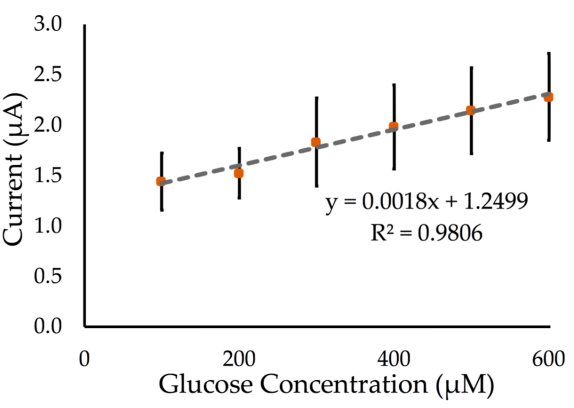

(b)

Figure 9. Amperometric titration of glucose concentration measured at a single step potential of $0.5 \mathrm{~V}$. (a) Amperometric current-time measurement of glucose detection using electrodes modified with rGO-PEDOT:PSS-GOx. Glucose concentrations were increased incrementally in 100-s time intervals. (b) Calibration curve derived from the amperometric measurements taken from SPCE electrodes modified with rGO-PEDOT:PSS ( $\mathrm{n}=3$ ). The plots were fitted linearly throughout the measured glucose range $(100 \mu \mathrm{M}-600 \mu \mathrm{M})$ with an $\mathrm{R}$-squared value of 0.9806 .

Table 1 compares the limit of detection of several glucose oxidase-based sensors. Notably, modifying the SPCE with ionic liquid was shown to improve its limit of detection significantly [47]. However, limited access to this method could possibly limit rapid prototyping and mass fabrication of biosensors. Previous work has also reported lower limits of detection of other graphene-based glucose sensors [48]; however, these sensors are mostly based on glassy carbon electrodes. Screen-printed carbon electrodes appeal to the development of biosensors owing to their cost-effectiveness and ease of miniaturization. 
Table 1. Sensitivity and limit of detection comparison of a few selected glucose enzymatic sensors (glucose oxidase). PVDF: polyvinylidene, $\mu$ PAD: paper-based analytical device, 4-APBA: 4-aminophenylboronic acid, NRs: nanorods, ITO: indium tin oxide, Pt: platinum, PANI: polyaniline, AuNPs: gold nanoparticles, Gr: graphene, IL: ionic liquid, N/D: not described.

\begin{tabular}{llcccc}
\hline \multicolumn{1}{c}{ Electrode } & Method & $\begin{array}{c}\text { Sensitivity } \\
\left(\mu \mathbf{A} /\left(\mathbf{m M} \cdot \mathbf{c m}^{2}\right)\right)\end{array}$ & $\begin{array}{c}\text { LoD } \\
(\mathbf{m M})\end{array}$ & References \\
\hline 1 & GOx/rGO/IL- SPE & $\mathrm{CV}$ & 22.78 & 0.001 & {$[47]$} \\
\hline 2 & $\mathrm{PVDF} / \mathrm{Ag} / \mathrm{GOx}$ & Capacitive & $\mathrm{N} / \mathrm{D}$ & 13 & {$[49]$} \\
\hline 3 & $(\mu \mathrm{PAD}) \mathrm{GOx} / 4-\mathrm{APBA} /$ cellulose-modified SPCE & $\mathrm{CV}$ & $\mathrm{N} / \mathrm{D}$ & 0.86 & {$[50]$} \\
\hline 4 & Nafion/GOx/ZnO NRs/ITO & $\mathrm{CV}$ & 48.75 & 0.06 & {$[51]$} \\
\hline 5 & GOx/Pt-graphite SPE & $\mathrm{CV}$ & 105 & 0.01 & {$[52]$} \\
\hline 6 & Gr/PANI/AuNPs/GOx/SPCE & $\mathrm{DPV}$ & 20.32 & 0.1 & {$[53]$} \\
\hline 7 & rGO-PEDOT:PSS-GOx/SPCE & $\mathrm{CV}$ & 57.3 & 0.0868 & This work \\
\hline
\end{tabular}

Nevertheless, refinements can be pursued in improving our glucose detection using rGO-PEDOT:PSS as the transducer. This is particularly true for improvising ways to include glucose oxidase or other enzymes that can improve methods in detecting glucose [11], as well as translating its signal through the rGO-PEDOT:PSS transducer.

\section{Conclusions}

Modification of commercially cheap screen-printed carbon electrodes brings an attractive alternative that allows us to improve the transfer kinetics of SPCEs. We have shown here that PEDOT:PSS forms a tight matrix that is interspersed between the rGO layers. This allows PEDOT to form a $\pi-\pi$ interaction with the surface of $\mathrm{rGO}$, which could improve conductivity. This work also shows that modifying the electrode surface with a composite of reduced graphene oxide and PEDOT:PSS (rGO-PEDOT:PSS) can improve signal transduction at the electrolyte-electrode interface. It is shown that graphene oxide can be electrochemically reduced on an SPCE. The use of rGO-PEDOT:PSS is electrochemically better than the use of rGO alone. Preliminary work has also demonstrated that glucose oxidase can be incorporated into the composite matrix and detect changes in glucose concentration. It is possible to explore this potential further by either employing other preparation strategies or using other enzymes, which could improve detection.

Author Contributions: W.W.A.W.S. conceived and designed the experiments; H.F.A.G. performed the experiments; all authors were involved in the analyses of the data; F.A.-W. and W.W.A.W.S. were involved in the interpretation of the experiments. W.W.A.W.S. contributed reagents/materials/analysis tools; F.A.-W. and W.W.A.W.S. wrote the paper with contributions from all authors.

Funding: This research was funded by FDNANO VENTURES LTD. contract research grant SP18-110-0372 and by THE INTERNATIONAL ISLAMIC UNIVERSITY MALAYSIA with grants from the IIUM Research Postdoctoral Fellowship Scheme, grant number RPDF18-002-0002, and the IIUM Research Initiative Grant Scheme, grant number RIGS17-011-0586.

Acknowledgments: We would like to thank Nurul Izzati Ramli for her input in the figure illustrations, and Nur Alya Batrisya Ismail for contributing to data collection.

Conflicts of Interest: The authors declare no conflict of interest. The funding sponsors had no role in the design of the study; in the collection, analyses, or interpretation of data; in the writing of the manuscript; and in the decision to publish the results. 


\section{References}

1. Hayat, A.; Marty, J.L. Disposable Screen Printed Electrochemical Sensors: Tools for Environmental Monitoring. Sensors 2014, 14, 10432-10453. [CrossRef] [PubMed]

2. González-Sánchez, M.I.; Gómez-Monedero, B.; Agrisuelas, J.; Iniesta, J.; Valero, E. Highly Activated Screen-Printed Carbon Electrodes by Electrochemical Treatment with Hydrogen Peroxide. Electrochem. Commun. 2018, 91, 36-40. [CrossRef]

3. Cui, G.; Yoo, J.H.; Lee, J.S.; Yoo, J.; Uhm, J.H.; Cha, G.S.; Nam, H. Effect of Pre-Treatment on the Surface and Electrochemical Properties of Screen-Printed Carbon Paste Electrodes. Analyst 2001, 126, 1399-1403. [CrossRef] [PubMed]

4. Guth, U.; Zosel, J.; Riedel, J.; Tran, T.N.; Berthold, M.; Vonau, C.; Sasum, U. New Developments in Electrode Materials for Electrochemical Sensors. In Advancement in Sensing Technology. Smart Sensors, Measurement and Instrumentation; Mukhopadhyay, S., Jayasundera, K., Fuchs, A., Eds.; Springer: Berlin/Heidelberg, Germany, 2013; pp. 181-189.

5. Pumera, M. Graphene in Biosensing. Mater. Today 2011, 14, 308-315. [CrossRef]

6. Sriprachuabwong, C.; Karuwan, C.; Wisitsorrat, A.; Phokharatkul, D.; Lomas, T.; Sritongkham, P.; Tuantranont, A. Inkjet-Printed Graphene-PEDOT:PSS Modified Screen Printed Carbon Electrode for Biochemical Sensing. J. Mater. Chem. 2012, 22, 5478-5485. [CrossRef]

7. Jo, G.; Choe, M.; Lee, S.; Park, W.; Kahng, Y.; Lee, T. The Application of Graphene as Electrodes in Electrical And Optical Devices. Nanotechnology 2012, 23, 112001. [CrossRef] [PubMed]

8. Chen, L.; Tang, Y.; Wang, K.; Liu, C.; Luo, S. Direct Electrodeposition of Reduced Graphene Oxide on Glassy Carbon Electrode and its Electrochemical Application. Electrochem. Commun. 2011, 13, 133-137. [CrossRef]

9. Clark, L.C., Jr. The Enzyme Electrode. In Biosensors: Fundamentals and Applications; Turner, A., Karube, I., Wilson, G.S., Eds.; Oxford University Press: New York, NY, USA, 1987; Volume 1, Chapter 1; pp. 3-12. ISBN 0-19-854724-2.

10. Thévenot, D.R.; Toth, K.; Durst, R.A.; Wilson, G.S. Electrochemical Biosensors: Recommended Definitions and Classification. Biosens. Bioelectron. 2001, 16, 121-131. [CrossRef]

11. Wang, J. Electrochemical Glucose Biosensors. Chem. Rev. 2008, 108, 814-825. [CrossRef] [PubMed]

12. Das, T.K.; Prusty, S. Review on Conducting Polymers and Their Applications. Polym. Plast. Technol. Eng. 2012, 51, 1487-1500. [CrossRef]

13. Huang, X.; Guo, H.; Yang, J.; Wang, K.; Niu, X.; Liu, X. Moderately Reduced Graphene Oxide/PEDOT:PSS as Hole Transport Layer to Fabricate Efficient Perovskite Hybrid Solar Cells. Org. Electron. Phys. Mater. Appl. 2016, 39, 288-295. [CrossRef]

14. Park, Y.; Soon Choi, K.; Young Kim, S. Graphene Oxide/PEDOT:PSS and Reduced Graphene Oxide/PEDOT:PSS Hole Extraction Layers in Organic Photovoltaic Cells. Phys. Status Solidi Appl. Mater. Sci. 2012, 209, 1363-1368. [CrossRef]

15. Bobacka, J. Conducting Polymer-Based Solid-State Ion-Selective Electrodes. Electroanalysis 2006, 18, 7-18. [CrossRef]

16. Groenendaal, B.L.; Jonas, F.; Freitag, D.; Pielartzik, H.; Reynolds, J.R. Poly(3,4-ethylenedioxythiophene) and Its Derivatives-Past, Present, and Future. Adv. Mater. 2000, 12, 481-494. [CrossRef]

17. Kim, J.Y.; Jung, J.H.; Lee, D.E.; Joo, J. Enhancement of Electrical Conductivity of Poly(3,4 -Ethylenedioxythiophene)/Poly(4-Styrenesulfonate) by a Change of Solvents. Synth. Met. 2002, 126, 311-316. [CrossRef]

18. Gerhard, H.; Jonas, F. Poly (Alkylenedioxythiophene)S-New, Very Stable Conducting Polymers. J. Phys. Org. Chem. 1992, 4, 116-118.

19. Pathak, C.S.; Singh, J.P.; Singh, R. Preparation of Novel Graphene-PEDOT:PSS Nanocomposite Films and Fabrication of Heterojunction Diodes with n-Si. Chem. Phys. Lett. 2018, 694, 75-81. [CrossRef]

20. Kirchmeyer, S.; Reuter, K. Scientific Importance, Properties and Growing Applications of Poly(3,4 -Ethylenedioxythiophene). J. Mater. Chem. 2005, 15, 2077-2088. [CrossRef]

21. Liu, Y.; Weng, B.; Razal, J.M.; Xu, Q.; Zhao, C.; Hou, Y.; Seyedin, S.; Jalili, R.; Wallace, G.G.; Chen, J. High-Performance Flexible All-Solid-State Supercapacitor from Large Free-Standing Graphene-PEDOT/PSS Films. Sci. Rep. 2015, 5, 1-11. [CrossRef] [PubMed] 
22. Lan, Z.; Gao, S.; Wu, J.; Lin, J. High-performing Dye-Sensitized Solar Cells Based on Reduced Graphene Oxide/PEDOT-PSS Counter Electrodes with Sulfuric Acid Post-Treatment. J. Appl. Polym. Sci. 2015, 132, 1-5. [CrossRef]

23. Yan, D.; Liu, Y.; Li, Y.; Zhuo, R.; Wu, Z.; Ren, P.; Li, S.; Wang, J.; Yan, P.; Geng, Z. Synthesis and Electrochemical Properties of MnO2/rGO/PEDOT:PSS Ternary Composite Electrode Material for Supercapacitors. Mater. Lett. 2014, 127, 53-55. [CrossRef]

24. Islam, M.M.; Chidembo, A.T.; Aboutalebi, S.H.; Cardillo, D.; Liu, H.K.; Konstantinov, K.; Dou, S.X. Liquid Crystalline Graphene Oxide/PEDOT:PSS Self-Assembled 3D Architecture for Binder-Free Supercapacitor Electrodes. Front. Energy Res. 2014, 2, 1-11. [CrossRef]

25. Zhang, Y.; Wu, C.; Zhang, J. Interactions of Graphene and Graphene Oxide with Proteins and Peptides. Nanotechnol. Rev. 2013, 2, 27-45. [CrossRef]

26. Pandit, S.; De, M. Interaction of Amino Acids and Graphene Oxide: Trends in Thermodynamic Properties. J. Phys. Chem. C 2017, 121, 600-608. [CrossRef]

27. Park, J.; Kim, H.K.; Son, Y. Glucose Biosensor Constructed from Capped Conducting Microtubules of PEDOT. Sens. Actuators B Chem. 2008, 133, 244-250. [CrossRef]

28. Lee, S.B.; Lee, S.M.; Park, N.I.; Lee, S.; Chung, D. Preparation and Characterization of Conducting Polymer Nanocomposite with Partially Reduced Graphene Oxide. Synth. Met. 2015, 201, 61-66. [CrossRef]

29. Pei, S.; Cheng, H.-M. The Reduction of Graphene Oxide. Carbon 2012, 50, 3210-3228. [CrossRef]

30. Berendjchi, A.; Khajavi, R.; Yousefi, A.A.; Yazdanshenas, M.E. Improved Continuity of Reduced Graphene Oxide on Polyester Fabric by Use of Polypyrrole to Achieve a Highly Electro-Conductive and Flexible Substrate. Appl. Surf. Sci. 2016, 363, 264-272. [CrossRef]

31. Chen, T.; Qiu, J.; Zhu, K.; Li, J.; Wang, J.; Li, S.; Wang, X. Ultra High Permittivity and Significantly Enhanced Electric Field Induced Strain in PEDOT:PSS-RGO@PU Intelligent Shape-Changing Electro-Active Polymers. RSC Adv. 2014, 4, 64061-64067. [CrossRef]

32. Abdolhosseinzadeh, S.; Asgharzadeh, H.; Seop Kim, H. Fast and Fully-Scalable Synthesis of Reduced Graphene Oxide. Sci. Rep. 2015, 5, 10160. [CrossRef] [PubMed]

33. Obreja, A.C.; Iordanescu, S.; Gavrila, R.; Dinescu, A.; Comanescu, F.; Matei, A.; Danila, M.; Dragoman, M.; Iovu, H. Flexible Films Based on Graphene/Polymer Nanocomposite with Improved Electromagnetic Interference Shielding. In Proceedings of the 2015 International Semiconductor Conference (CAS), Sinaia, Romania, 12-14 October 2015; pp. 49-52.

34. Seekaew, Y.; Lokavee, S.; Phokharatkul, D.; Wisitsoraat, A.; Kerdcharoen, T.; Wongchoosuk, C. Low-Cost and Flexible Printed Graphene-PEDOT:PSS Gas Sensor for Ammonia Detection. Org. Electron. 2014, 15, 2971-2981. [CrossRef]

35. Nguyen Huynh, N.M.; Boeva, Z.A.; Smått, J.H.; Pesonen, M.; Lindfors, T. Reduced Graphene Oxide as a Water, Carbon Dioxide and Oxygen Barrier in Plasticized Poly(Vinyl Chloride) Films. RSC Adv. 2018, 8, 17645-17655. [CrossRef]

36. Ferrari, A.C.; Robertson, J. Interpretation of Raman Spectra of Disordered and Amorphous Carbon. Phys. Rev. B 2000, 61, 14095-14107. [CrossRef]

37. Yoo, D.; Kim, J.; Kim, J.H. Direct Synthesis of Highly Conductive Poly(3,4-Ethylenedioxythiophene): Poly(4-Styrenesulfonate) (PEDOT:PSS)/Graphene Composites and Their Applications in Energy Harvesting Systems. Nano Res. 2014, 7, 717-730. [CrossRef]

38. Rivnay, J.; Inal, S.; Collins, B.A.; Sessolo, M.; Stavrinidou, E.; Strakosas, X.; Tassone, C.; Delongchamp, D.M.; Malliaras, G.G. Structural Control of Mixed Ionic and Electronic Transport in Conducting Polymers. Nat. Commun. 2016, 7, 1-9. [CrossRef] [PubMed]

39. Wang, Y.; Chen, Y.; Lacey, S.D.; Xu, L.; Xie, H.; Li, T.; Danner, V.A.; Hu, L. Reduced Graphene Oxide Film with Record-High Conductivity And Mobility. Mater. Today 2018, 21, 186-192. [CrossRef]

40. Cui, L.; Gao, J.; Xu, T.; Zhao, Y.; Qu, L. Polymer/Graphene Hybrids for Advanced Energy-Conversion and -Storage Materials. Chem. Asian J. 2016, 11, 1151-1168. [CrossRef] [PubMed]

41. Kertesz, M. Pancake Bonding: An Unusual Pi-Stacking Interaction. Chem. Eur. J. 2019, 25, 400-416. [CrossRef] [PubMed]

42. Zhu, Y.; Murali, S.; Cai, W.; Li, X.; Suk, J.W.; Potts, J.R.; Ruoff, R.S. Graphene and Graphene Oxide: Synthesis, Properties, and Applications. Adv. Mater. 2010, 22, 3906-3924. [CrossRef] [PubMed]

43. Wilson, R.; Turner, A.P.F. Glucose Oxidase: An Ideal Enzyme. Biosens. Bioelectron. 1992, 7, 165-185. [CrossRef] 
44. Analytical Methods Committee. Recommendations for the Definition, Estimation and Use of the Detection Limit. Analyst 1987, 112, 199-204. [CrossRef]

45. Lavín, Á.; de Vicente, J.; Holgado, M.; Laguna, M.F.; Casquel, R.; Santamaría, B.; Maigler, M.V.; Hernández, A.L.; Ramírez, Y. On the Determination of Uncertainty and Limit of Detection in Label-Free Biosensors. Sensors 2018, 18, 2038. [CrossRef] [PubMed]

46. Bollella, P.; Gorton, L.; Ludwig, R.; Antiochia, R. A Third Generation Glucose Biosensor Based on Cellobiose Dehydrogenase Immobilized on a Glassy Carbon Electrode Decorated with Electrodeposited Gold Nanoparticles: Characterization and Application in Human Saliva. Sensors (Switzerland) 2017, 17, 1912. [CrossRef] [PubMed]

47. Ping, J.; Wang, Y.; Fan, K.; Wu, J.; Ying, Y. Direct Electrochemical Reduction of Graphene Oxide on Ionic Liquid Doped Screen-Printed Electrode and its Electrochemical Biosensing Application. Biosens. Bioelectron. 2011, 28, 204-209. [CrossRef] [PubMed]

48. Wang, F.; Liu, L.; Li, W.J. Graphene-Based Glucose Sensors: A Brief Review. IEEE Trans. Nanobiosci. 2015, 14, 818-834. [CrossRef] [PubMed]

49. Hartono, A.; Sanjaya, E.; Ramli, R. Glucose Sensing Using Capacitive Biosensor Based on Polyvinylidene Fluoride Thin Film. Biosensors 2018, 8, 12. [CrossRef] [PubMed]

50. Rungsawang, T.; Punrat, E.; Adkins, J.; Henry, C.; Chailapakul, O. Development of Electrochemical Paper-Based Glucose Sensor Using Cellulose-4-Aminophenylboronic Acid-Modified Screen-Printed Carbon Electrode. Electroanalysis 2016, 28, 462-468. [CrossRef]

51. Ridhuan, N.S.; Abdul Razak, K.; Lockman, Z. Fabrication and Characterization of Glucose Biosensors by Using Hydrothermally Grown ZnO Nanorods. Sci. Rep. 2018, 8, 1-12. [CrossRef] [PubMed]

52. Abellán-Llobregat, A.; Jeerapan, I.; Bandodkar, A.; Vidal, L.; Canals, A.; Wang, J.; Morallón, E. A Stretchable and Screen-Printed Electrochemical Sensor for Glucose Determination in Human Perspiration. Biosens. Bioelectron. 2017, 91, 885-891. [CrossRef] [PubMed]

53. Kong, F.Y.; Gu, S.X.; Li, W.W.; Chen, T.T.; Xu, Q.; Wang, W. A Paper Disk Equipped with Graphene/Polyaniline/Au Nanoparticles/Glucose Oxidase Biocomposite Modified Screen-Printed Electrode: Toward Whole Blood Glucose Determination. Biosens. Bioelectron. 2014, 56, 77-82. [CrossRef] [PubMed]

(C) 2019 by the authors. Licensee MDPI, Basel, Switzerland. This article is an open access article distributed under the terms and conditions of the Creative Commons Attribution (CC BY) license (http://creativecommons.org/licenses/by/4.0/). 